\title{
DESIGNING FOR SCIENCE CENTER EXHIBITIONS - A CLASSIFICATION FRAMEWORK FOR THE INTERACTION
}

\author{
J. Wideström $\bowtie$ \\ Chalmers University of Technology, Sweden \\ $\triangle$ josef.widestrom@chalmers.se
}

\begin{abstract}
While designing and discussing exhibitions in science centers, common conceptual framework is needed. This paper provides a framework based on participation, virtuality, and collaboration, and two models - a Rubik's cube model and a Scatter plot space. They are suitable tools for analysis and overview of existing and planned exhibitions, as well as for conceptual analysis during the design process. The classification and the models for the interaction have been developed in a research by design process, where 45 prototypes have been designed, exhibited and tested.
\end{abstract}

Keywords: design for $x(D f X)$, design tools, interaction design, virtual space, science centers

\section{Introduction}

Designing for science center exhibitions is a challenging task that exposes important design issues and puts concepts and methods to the test. Science center exhibits are typically highly interactive, involve a wide range of target groups, have a specific purpose of being educational and engaging, and set requirements for robustness and ethics. The exhibits open up for different modes of embodied interaction, where users can participate and collaborate in different forms and degrees, and where digital and physical design materials and spaces merge. Science center also works as a stage for transdisciplinarity, where natural science meets arts and humanities. This paper proposes a classification of the interaction in science center exhibits, together with two models that can support the discussion and evaluation of existing exhibit designs, as well as the analysis of concepts in the design process.

Architectural design and interaction design merge as our physical and digital spaces become interdependant and co-existing (McCullough, 2004). The forms of computer technology are changing and becoming part of our physical space, and as computation is integrated in physical space, interaction designers are increasingly working with spatial digital artifacts (Dourish, 2004). With the development of new technology and "smart" systems, interaction design becomes an indispensable dynamic in life (Lia; Zhang, 2019). Adding spatial aspects, interaction design brings the interface out into the room and expands the role of the interaction designer to develop structures and form as well as compose situations for its users (Eriksson, 2011). Interaction designers are creating situations in both physical and digital space using IT as the primary design material, which could be considered as non-physical and non-spatial. However, when designing spatial interfaces, physical materials come into play and designers must understand how the properties of IT relate to spatial properties and boundaries. When it comes to designing virtual spaces, IT becomes a highly spatial design material. Novel concepts, such as Augmented 
Reality, Mixed Reality and Substitutional Reality (Simeone et al., 2015) show that digitally produced virtual spaces and actual physical spaces can merge.

Public knowledge institutions, such as museums and science centers, are transforming the way the scientific and artistic content is displayed and communicated. New media give new possibilities of interaction and experience, where spatial aspects need to be addressed. Virtual spaces complement and expand the physical spaces of science centers, both in the design process and in the realized exhibitions (Eriksson and Wideström, 2014; 2015). The merge of physical and virtual spaces is particularly interesting to study in science center settings, since the science center is a highly interactive environment, dedicated for learning activities, and with a wide spectrum of user groups. In a science center, there is also a wide range of possibilities for the scientific content to be displayed and interacted with. The relation between physical and virtual space is contextual and depending on other relations. In the case of science center exhibitions, this context is formed by the scientific content, the staging of this content and the users' interaction with the content and each other. Theoretical design research on science centers, summarized in the DEX framework (Ocampo-Agudelo et al., 2017), suggests that the visitor experience in a science center is based on five building blocks; physical, institutional, personal, relational, and social. This framework analyses the key factors for the learning experience in science centers. Also, other research on the topic of analysing exhibits (Rennie, McClafferty, 1995; Mehmet, 2016; Koran et al, 1983) is focused on the teaching and learning of science. We argue for a need to analyse science center exhibits from a design perspective, focusing on the aspects of interaction.

Universeum is Scandinavia's largest science center, with more than 500.000 visitors every year. It includes an aquarium and terrarium as well as a rainforest with tropical animals. The science center has also exhibitions about space, health, technology, and more. Universeum has a strong pedagogical profile, with over 60.000 school children visiting yearly. These school visits are related to the curricula on different levels of the education regarding natural sciences. Universeum's mission is to make young people interested in and to teach them about technology and science and inspire them to pursue a career within those fields. Universeum also has a mission from the city of Gothenburg to be an attractive place to visit for citizens and tourists (Universeum, 2015). The variety of audiences and ways of interaction present a background for setting up different types of exhibits. In order to facilitate conceptualisation and communication, a classification framework is proposed.

\section{Method}

The methodology for developing a classification and models for the interaction is research by design. New knowledge in the intended domain (interaction design) is created through design work in the related context (science centers). Here the methodology is balanced between inspiration-based design research and information-based design research (Sanders, 2005), where knowledge is built upon experimentation in combination with investigation. As such, the methodology relies on the designing of prototypes as a generator of knowledge (Stappers, 2007). Unlike the theoretical design research approach, this research has been conducted through design work. The focus is on the relational building block, as presented in the DEX framework, giving the interaction between users and exhibits a central role.

Different interactive prototypes for exhibits have been developed, displayed and tested at this science center (IDXPO, 2019). These prototypes have worked as probes and inspiration for the science center, with 10-13 temporary installations presented at an annual exhibition. Each year the projects have followed a certain theme for exploring particular aspects of designing for science center exhibits, where the themes have emerged from discussions with project leaders at Universeum. During 2016-2019 Universeum has developed 45 prototypes of exhibits, in collaboration with researchers, teachers and students at the Interaction Design \& Technology master's program at Chalmers University of Technology. The design teams of 3-6 master students and one teacher/researcher have ideated and prototyped from the project themes. The prototypes have been showcased as interactive installations and tested with hundreds of visitors each (IDXPO, 2019), with around 4000 visitors in total per exhibition. These temporary exhibits have been an important part of the innovation process at this science center. Some of the prototypes have been developed into actual exhibits and others have worked as inspiration for future development.The author's contribution has been to initiate the projects, develop yearly themes in collaboration with 
Universeum and then supervise and lead the projects during the eight weeks' project periods. Last four years the projects have been dedicated to the following themes:

- 2016 - The Interactive Science Center

- 2017 - The Participatory Universeum, and The Virtual Universeum

- 2018 - New Technology

- 2019 - Showing the Invisible

The evaluation of the results of these four instances of project work at Universeum shows that some aspects of interaction are particularly interesting to discuss. The first aspect concerns the level of user participation, whether the content of the exhibition is predetermined or co-created. The second aspect concerns the level of virtuality, that is if the interaction mainly takes place in actual physical space or in virtual space. The third aspect concerns the level of collaboration, hence how collaborative the exhibits are in terms of users interacting with each other or not. Other aspects of interaction have also been discussed, such as for example different target groups, different pedagogy, and different media, that all affect the interaction. However, for the simplicity and clarity we have selected to focus on three dimensions. These dimensions, as described in this paper, were chosen by the authors for their capacity to frame the interaction and include other aspects. The observations of the realized installations have been done by the author as supervisor of the projects, with input from the design teams and the written reports (IDXPO, 2019). The method for collecting the data for the classifications is general and can be adapted to different project organisations.

\section{A classification of the interaction}

Here a model of three dimensions of interaction is presented, creating a framework for analysis and classification of different types of interactions and media in the context of science center exhibitions. This classification is based on three aspects of interaction, where the first concerns the level of participation, the second the level of virtuality, and the third the level of collaboration. The classification can be summarized in these dimensions:

1. STATIC vs. PARTICIPATORY CONTENT

2. PHYSICAL vs. VIRTUAL SPACE

3. INDIVIDUAL vs. COLLABORATIVE INTERACTION

\subsection{Static vs. Participatory content}

The level of participation concerns the users' influence over the content of the exhibit:

- Static [St]: Content is predetermined and it is up to the users to discover it.

- Participatory [Pa]: Content is co-created by the users.

- Static/Participatory [SP]: Some content is predetermined and other content is co-created.

In traditional science center and museum exhibits, the institution provides content for visitors to consume. Designers focus on making the content consistent so that every visitor, regardless of interests, receives a good experience with scientific authenticity in focus. In contrast, in participatory projects, the institution supports multi-directional content experience and creation. The institution serves as a multi-disciplinary stage that connects different users who act as content creators, distributors, consumers, critics, and collaborators. This means the institution cannot guarantee the consistency of visitor experiences. Instead, the institution provides opportunities for diverse visitor co-produced experiences (Simon, 2010). In some cases, the exhibits allow a mix between traditional provided content and only partly co-created content. Here the user participation, involvement and engagement are in focus.

The more participatory exhibits $[\mathrm{Pa}]$ let users contribute with their own knowledge, personality, and creativity. This is shown for example in the TangiWeb project, where children learn how to design websites through a tangible interface in an exploratory experience. The Releaf project lets users relax in a meditative greenhouse environment where touching the plants creates combinations of sound effects. In the RoboPop project, users play musical instruments collaboratively. These two projects aimed at teaching about sensor technology through a high level of user participation. This participatory 
approach gives the opportunity to engage visitors also after the visit to Universeum. Users of the TangiWeb installation can share and continue to edit their website from home and users of the RoboPop installation can continue to join the "band" and also control the instruments from home, knowing that the sounds they are making are actually being played in real-time at Universeum.

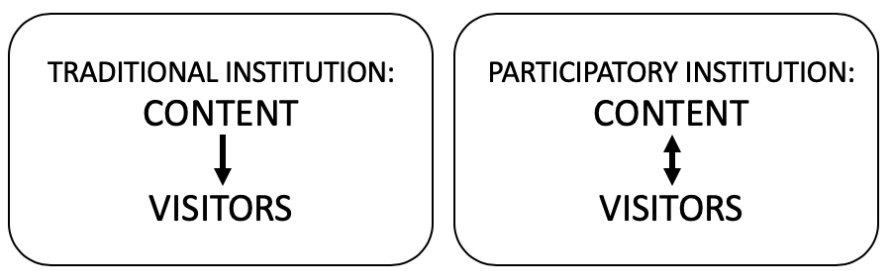

Figure 1. Participation (Wideström, 2019, from Simon, 2010)

The content of the more static exhibits [St] is defined before the interaction, and it is up to the user to find, experience and explore this content. These exhibits are generally based on a task or quest for the user to solve. The science center has better control of the scientific validity and needs to make less trade-offs between science and entertainment. Such static exhibits can be done in many different forms, ranging from posters of text to highly interactive virtual environments. SurgeonAcademy is a simulation setup for operations, where users have to complete a surgical task. LaserGolf is a physical labyrinth with mirrors, where users lead a laser beam from start to finish. In the MuffinOrChihuahua project, users learn about AI and neural networks through a simple and fun game, an informative video and a test. These projects show that "static" does not necessarily mean "boring".

Table 1. [Pa] vs. [St]

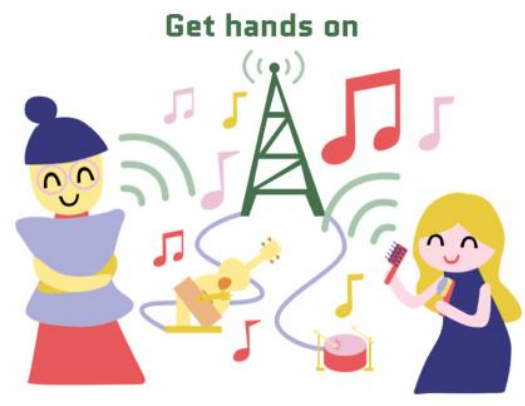

[Pa]: RoboPop, 2018

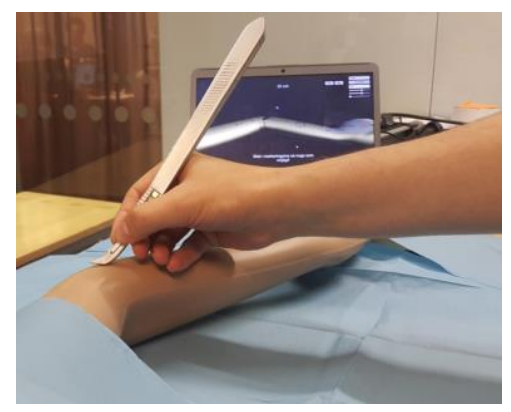

[St]: Surgeon Academy, 2017

\subsection{Physical vs. Virtual space}

The level of virtuality concerns how much of the interaction that takes place in the actual physical space vs in the potential virtual space. When one interacts with a computer-generated virtual space, the screen displays an image that depends on physical interactions happening between the actor (user) and the computer, at the level of hardware. The virtual space is nowhere in actuality of the outside world, but is nonetheless real and can be interacted with as it is present in our cognition. Simultaneously, the actor is present in a physical space, where the screen works as a window into the virtual world. An actor who interacts with both a physical and a virtual space simultaneously, can be said to be present in a physicalvirtual space (Wideström, 2019). It is distinguished with respect to the degree of physicality/virtuality:

- Physical [Ph]: Interaction between users and content happen in the actual physical space.

- Virtual [Vi]: Interaction between users and content happen in the potential virtual space.

- Physical-Virtual [PV]: The interaction take place in a physical-virtual space.

A physical exhibit at a science center allows hands-on interaction, typically with levers, wheels, building blocks, and sometimes even sand or water. Sometimes the installation lacks interactivity, but is rather a poster, a sculpture or a display of objects. A virtual space of a science center might be a visualization or virtualization of some kind. It can also be a computer-based simulation, an artificial intelligence or a 
computer game. The website of the science center is also a space for the virtual science center. The social media space of a science center is also a virtual space that exists, partly out of control for the management. Some exhibits use a combination of physical and virtual spaces and elements, such as physical landscapes projected with a digital augmenting overlay.

Virtual space is seen as separate from physical space in an architectural (structural) sense, but the two worlds co-exist in an interdependent relation. An actor/user/observer can experience presence in both physical and virtual space simultaneously, through an interaction space that involves both physical and virtual space, meaning that this actor interacts in physical-virtual space through an embodied interaction (Figure 2). Also, using augmented and mixed reality technologies can create a physicalvirtual space for interactive learning (Cuendet et al., 2013).

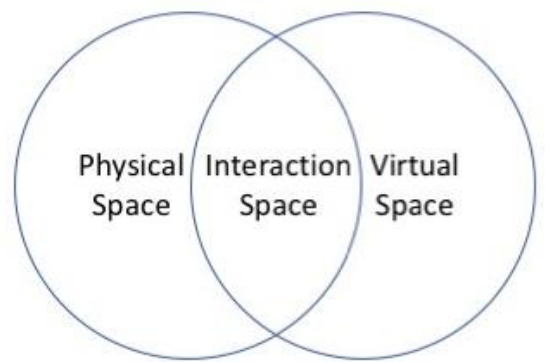

Figure 2. Physical and Virtual Space (Wideström, 2019)

The more virtual exhibits [Vi] highlight the possibility to "show the invisible", and let users see and interact with phenomena that cannot be seen with our human senses in the actual world. In the InteractiveMirror installation, the users can see the skeleton inside their own body (or so it seems) and move and play around in front of the mirror. This exploratory approach is typical for exhibits that take place in virtual space. The virtual exhibits can also be in the form of games, like in the OceanCleanUp or the RadiationPlatformer projects. Here the gamification is meant to evoke a higher motivation for the user to experience and learn about the targeted scientific content. An advantage with virtual installations is that the virtual spaces are digital and such not fixed to a physical location (even though some of the interfaces might be), having the potential to be showcased outside the physical space of the science center. Some virtual science projects can also be adapted for the Universeum website, connecting the experience to before and after the visit.

The more physical and hands-on installations $[\mathrm{Ph}]$ take advantage of the sense of haptic touch and tactile touch, and also other senses than vision. In these exhibits the embodied interaction gives feedback mainly in physical space and not through a display or other digital interface. In contrast to the virtual space, the physical space has scale, gravity and materiality. In the WindiCity project, users build their own physical windmills that are compared in relation to the amount of electricity generated. In the WaveLab setup, users interact with sound waves, vibrations and resonance. In the CyborgBox, users are blindfolded and equipped with proximity sensors that replace their vision and help them walk through a labyrinth in analogy with the senses of a bat. This is a good example how physical exhibits can support experiential interaction and not only give concrete feedback.

Table 2. [Vi] vs. [Ph]



[Vi]: Interactive Mirror, 2016

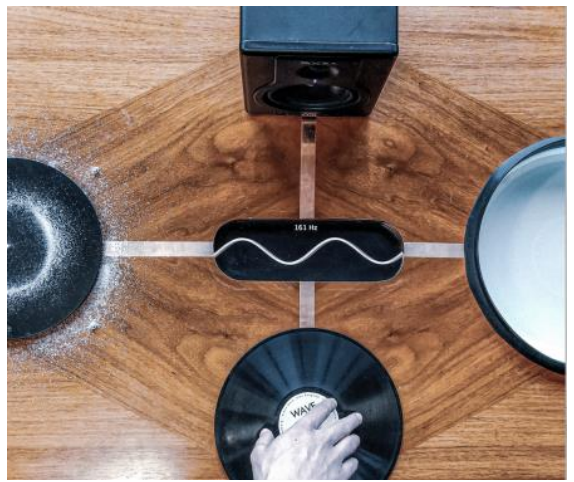

[Ph]: Wave Lab, 2019 


\subsection{Individual vs. Collaborative interaction}

The level of collaboration concerns the social interaction between the users.

- Individual [In]: Users interact individually with the content.

- Collaborative [Co]: Users collaborate in the interaction with the content.

- Individual/Collaborative [IC]: Users can but do not need to collaborate.

Regarding social interaction, science center exhibits range from individual to collaborative (Figure 3, where red triangles symbolise the content and blue squares the interface). Some installations are based on a completely individual interactivity with the content (A). Others allow social interactivity between users that are interacting separately and individually (B). Other exhibits require or induce collaboration in the interaction with the content $(\mathrm{C})$. A fourth kind of exhibits is basically a communication tool that allow users to collaborate through the installation (D) (Karlén, 2017).

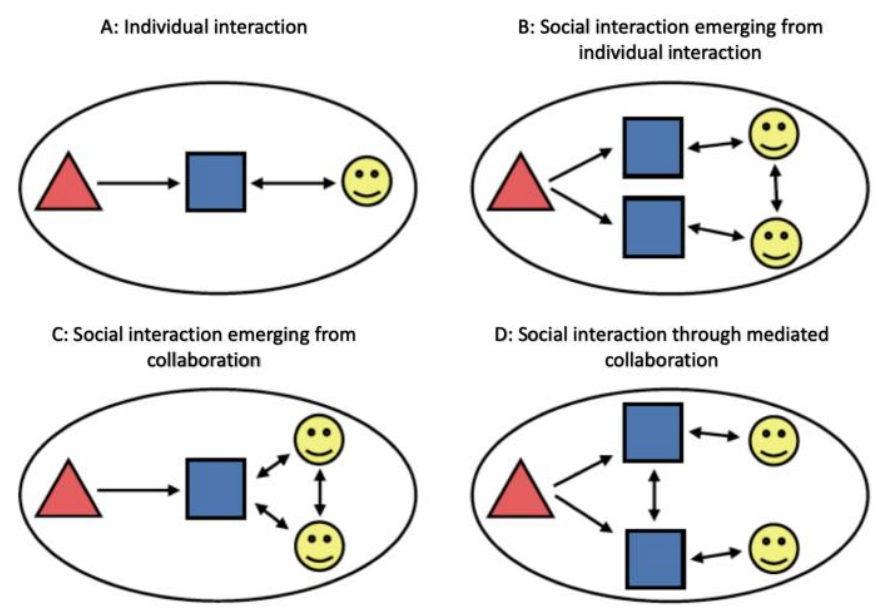

Figure 3. Collaboration (Karlén, 2017)

Collaboration in science center exhibits can happen in many different ways. Installations can be designed for collaborative interaction [Co], either so that they invite users to work together or that they require two or more users to interact through or with the installation. The SenseOfTaste project aim at teaching children about sensor technology in a food cooking setting. This activity can be performed individually but is more engaging and rewarding to experience and play in a small group. The VREscape project has a meta-technological focus, teaching users about VR technology in a collaborative VR game. The interesting twist is that only one user is trapped in the virtual escape room, while the other 3-4 persons are "outside" in the physical space, watching and helping the trapped person to escape. So here the collaboration ties the physical and virtual space together in an interesting way. A third way to collaborate is shown in the TwinStarSupernova project, where two persons need to collaborate in a physical interaction with a virtual environment, in this case on two Wii balance boards controlling two stars collapsing into a black hole.

The less collaborative exhibits [In] focus on individual interaction. These installations are targeted towards people who do not want to engage in social interaction while playing or learning about natural science. Some content could also benefit from being interacted with individually. A science center needs a variety in the spectrum of social interaction, from individual to collaborative. The ARubik project aims at teaching users to solve a $2 \times 2$ Rubik's cube, using AR technology to provide the user with a step-by-step guide. This installation requires mental focus on the task and does not benefit from disturbing noise or comments from others. In the Animal Vision project, a user gets to experience how different animals perceive the world visually, using different digital filters and image distortion. In one setting the user sees himself/herself in a mirror, from a dog's perspective. The SNAP project aims at teaching teenagers about social media technology, using a physical photo booth as analogy for the Snapchat app. Here the experience and interaction are very much individual, but the end result with a printed miniature portrait turned out to be popular to share on social media. 
Table 3. [Co] vs. [In]

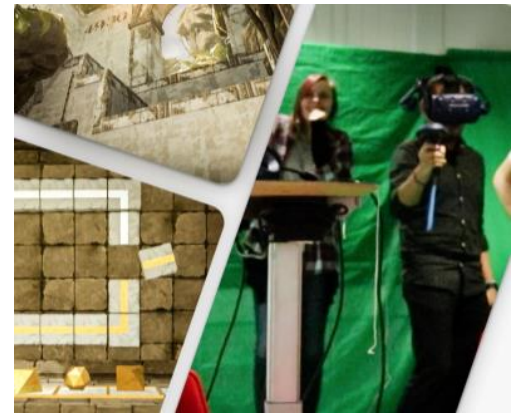

[Co]: VR Escape, 2018

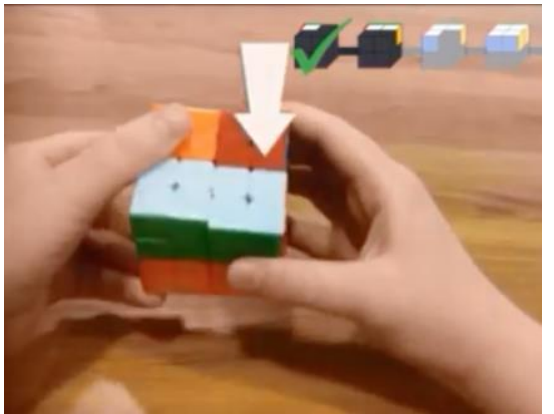

[In]: ARubik, 2016

\subsection{Classified list of exhibits}

For a list of all 45 interactive installations, see Appendix A. This overview shows the effectiveness when it comes to picking out for example all "Individual" exhibits or cross-referencing the "Participatory" with the "Physical" exhibits. However, the aim of this case has not been to show statistic results of quantitative data. The focus is rather on showing these dimensions, as a conceptual framework for making observations. The classification can be used as a tool for discussions and analyses of interactive installations at a science center.

\section{Models for classification}

\subsection{The Rubik's cube}

These three dimensions (participation, virtuality, collaboration) with three values $[\mathrm{X}, \mathrm{XY}, \mathrm{Y}]$ spans a $3 \times 3 \times 3$ cube that is illustrated in a Rubik's cube type of figure (Figure 4).

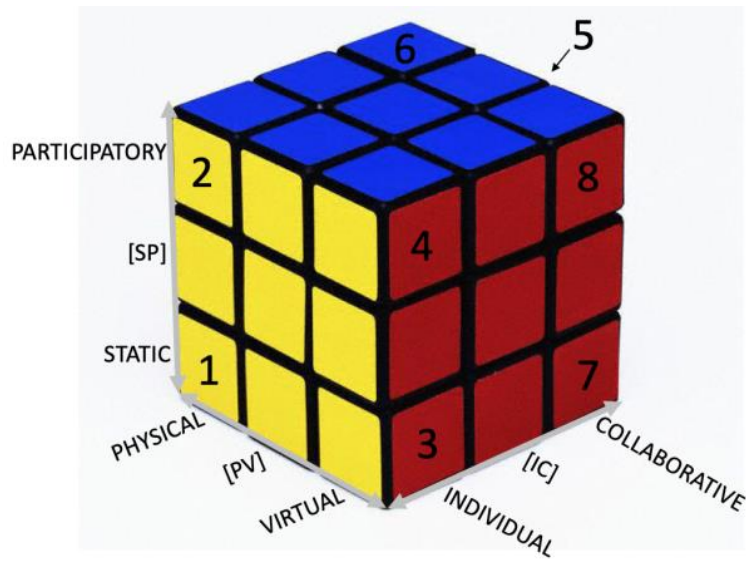

Figure 4. The Rubik's cube model

This model is proposed to classify and analyse the interactive exhibits. There are eight corner pieces in this cube, each representing an "extreme" type of exhibit. Here follows a list of all eight corners of the model, with examples of typical exhibits:

1. Static, Physical, Individual [St,Ph,In]: A one-person physical puzzle.

2. Participatory, Physical, Individual $[\mathrm{Pa}, \mathrm{Ph}, \mathrm{In}]:$ A handicraft workshop.

3. Static, Virtual, Individual [St,Vi,In]: A math quest game.

4. Participatory, Virtual, Individual [Pa,Vi,In]: A 3D-modelling sandbox.

5. Static, Physical, Collaborative [St,Ph,Co]: An escape room with a quest.

6. Participatory, Physical, Collaborative $[\mathrm{Pa}, \mathrm{Ph}, \mathrm{Co}]$ : A room with building blocks.

7. Static, Virtual, Collaborative [St,Vi,Co]: A collaborative computer puzzle game.

8. Participatory, Virtual, Collaborative $[\mathrm{Pa}, \mathrm{Vi}, \mathrm{Co}]$ : A "build your city" social computer game. 
Slices and sections can also be made in the Rubik's Cube model. Such as "Yellow side" would mean all types with individual interaction, "Red side" would point at all virtual exhibits, and "Blue side" would refer to all participatory exhibits. It is important to point out that the $100 \%$ extremes of this model are rare in reality. Regarding virtuality, all "Virtual" exhibits need to take place in the physical space using physical devices and require some sort of physical interaction. All "Physical" exhibits are most likely also represented in some virtual space, such as the science center's website or social media. Regarding participation all "Static" exhibits can be challenged and discussed that make viewers part of the production of meaning, and all "Participatory" exhibits have some limitations and requirements that set the frame for what is possible. And finally, regarding social aspects, all "Individual" exhibits can be affected by other users standing by or influencing the interaction, and all "Collaborative" exhibits might be controlled more by individual interaction.

The Rubik's cube model is targeted on analysis and support of discussions around particular exhibits. The design of the model is based on the $3 \times 3 \times 3$ matrix, that metaphorically creates the rules of the game of analysis and discussion. Other connotations of the Rubik's cube design regard "pieces coming together", "solving a difficult task", and "seeing different sides". The actual Rubik's cube puzzle is static, physical, and individual in its interaction, implying that this model probes the classification process with such a tool. A Rubik's cube can literally be put "on the table" or brought along the exhibitions and be used hands-on in the discussion sessions at the science center.

\subsection{The scatter plot space}

For analysing multiple exhibits coming together in a thematic exhibition or for mapping the interaction profile of a whole science center, a more transparent and dynamic model is required. Here a scatter plot space is used to visualize the projects from 2016 and 2018 (Figure 5) using the data from Appendix A. More aspects can be mapped to this graph, for example point colours for intended target groups, or point shapes for scientific topics (Ware, 2000). In comparison to the Rubik's cube, this model is more dynamic and open to handling additional dimensions to the three on the axes that span the 3-D space. Data can be edited and the view can be manipulated by panning, rotating and zooming.

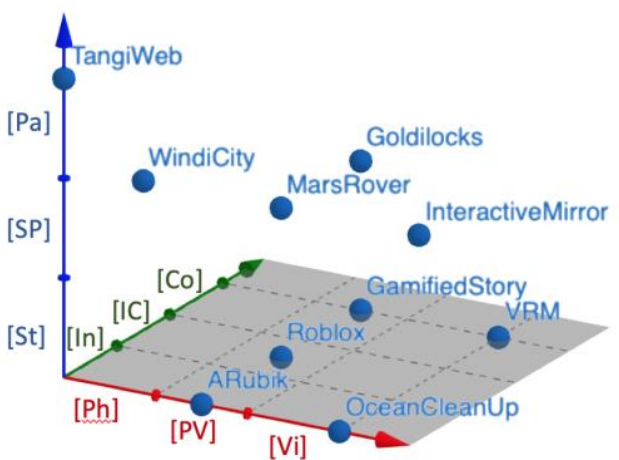

The Interactive Science Center, 2016

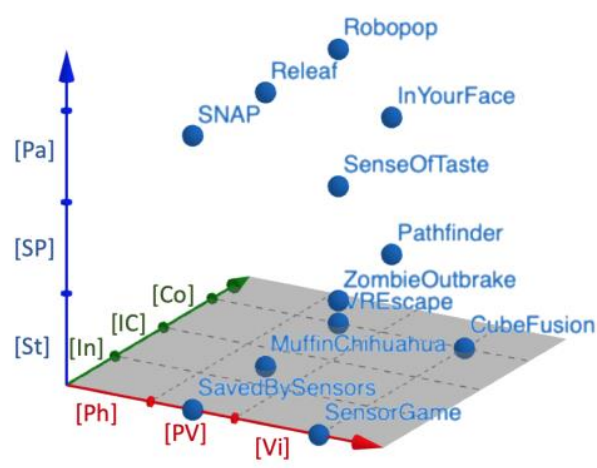

New Technology, 2018

Figure 5. The scatter plot space

This model is more targeted towards making an overview of existing and planned exhibits, and to analyse and map how the interaction works overall. It could also be used for comparing groups of exhibits. In the example here, it can be noted that the 2018 exhibition had a more Virtual and Participatory profile overall than the 2016 exhibition (Figure 5). As a tool, the scatter plot space is more participatory, virtual, and collaborative.

\section{Conclusion}

A science center needs a wide spectrum of ways of interaction in order to meet different needs and relate to different contexts and audiences. Proposed classification of interaction shows that we cannot say that one type of interaction is better than the other or that successful exhibitions differ in the 
dimensions of this framework. This classification is not a design guideline, but rather a model for bringing up important aspects of interaction. So, what type of interaction should we design for in a science center exhibition? The answer is: it depends.

Regarding participation, a highly participatory exhibit opens up for co-creation and involvement, while less user participation can secure better control over the communication of scientific facts. The aspect of participation highlights the problem of trade-off between science and entertainment components in a science center. Regarding the relation between physical and virtual space, the virtual exhibits can work as "windows" or "doors" into other worlds, seen from the physical environment. In these virtual spaces new agreements and experiences can be made. The user can see invisible phenomena such as temperature or electromagnetic fields, interact with quantum mechanics, or travel to other galaxies. However, the virtual spaces of the science center need to be related to the physical context. The understanding of a virtual installation depends on the surrounding physical space, and the user experience is formed in a physical-virtual interaction space. Regarding collaboration, social interaction with other users can lead to stronger user involvement and a higher "fun factor" in the learning experience. However, social interaction can also be experienced as disturbing when focusing on solving difficult tasks and learning about scientific concepts. Therefore, the development of science center exhibitions needs tools for analyzing and understanding the different dimensions of interaction.

The contribution of this paper is to provide designers and planners of science centers with a framework that can support design work and evaluation. The proposed models focus on three important dimensions of interaction: participation, virtuality, and collaboration. The Rubik's cube model is targeted on analysing particular exhibits, while the scatter plot space is more targeted towards making overviews. Together, the two models have the potential to support and facilitate work with the development of science center exhibitions focused on the interaction between users and the content. Future work will incorporate testing and evaluating the framework with users in different contexts of the science center.

\section{Acknowledgement}

I would like to give credit to all of the more than 200 master students of the Interaction Design and Technology programme at Chalmers University of Technology, that have put in a lot of ingenuity and hard work in realizing these 45 projects. Also, the support and discussions with teachers and researchers colleagues involved, particularly Prof. Gordana Dodig-Crnkovic, has been invaluable for the result. Finally, I want to thank the staff and management at Universeum for contributing with scientific input and practical help and for providing this unique arena for design and study of it results.

\section{References}

Ayar, M. (2016), "Examining the Effect of Our World Exhibit on Student Visitors: A Science Center Case", Science Education International, v27 n3 p419-436 2016

Cuendet, S. et al. (2013), "Designing augmented reality for the classroom", Computers \& Education, Vol. 68, pp. 557-569.

Dourish, P. (2004), "What we talk about when we talk about context", Personal and Ubiqut. Computing, Vol. 8, pp. 19-30.

Eriksson, E. (2011), “Spatial Explorations in Interaction Design”, Proceedings of Ambience'11 Conference.

Eriksson, E. and Wideström, J. (2014), "Staging the Interaction - Explorative Interventions for Engaging Citizens in the Development of Public Knowledge Institutions", Proceedings of Design Research Society's Conference.

Eriksson, E. and Wideström, J. (2015), "The Virtual Culture House - Shaping the Identity of a Public Knowledge Institution", Proceedings of The Value of Design Research Conference. Paris.

IDXPO (2019), Project website. [online] http://idxpo.se/

Karlén, J. (2017), "Learning with Digital Tools on Public Knowledge Institutions, A Literature Review based on Grounded Theory”, Göteborg University. Report, Vol. 2017 No. 106, pp. 36.

Koran, J., Longino, S. and Shafer, L. (1983), "A framework for conceptualizing research in natural history museums and science centers", JRST, Vol. 20 No. 4, pp. 325-339.

Liu, Y., Zhang, Q. (2019), “Interface Design Aesthetics of Interaction Design”. In: Design, User Experience, and Usability. Design Philosophy and Theory.

McCullough, M. (2004), Digital Ground: Architecture, Pervasive Computing, and Environmental Knowing, MIT Press Cambridge, MA. USA. 
Ocampo-Agudelo, J., Maya, J. and Roldán, A. (2017), “A Tool for the Design of Experience-Centered Exhibits in Science Centers", Science World Summit.

Rennie, L. and McClafferty, T. (1995), "Using visits to interactive science and technology centers, museums, aquaria, and zoos to promote learning in science", J Sci Teacher Educ, Vol. 6, pp. 175-185.

Sanders, E.B.-N. (2005), "Information, inspiration and co-creation". The 6th International Conference of the European Academy of Design. Bremen, Germany.

Simeone, A.L., Velloso, E., and Gellersen, H. (2015), "Substitutional Reality: Using the Physical Environment to Design Virtual Reality Experiences".

Simon, N. (2010), The Participatory Museum. [online] http://www.participatorymuseum.org

Stappers, P.J. (2007), "Doing design as a part of doing research". In: Michel, R. (Ed.), Design research now: essays and selected projects. Basel: Birkhäuser, pp. 81-91.

Universeum (2015), Versamhetsberättelse. Report 2015.

Ware, C. (2000), Information Visualization: Perception for design, Morgan Kaufmann Publishers.

Wideström, J. (2019), "The Transdisciplinary Nature of Virtual Space”, Book chapter in Augmented Reality, Virtual Reality, and Computer Graphics. AVR 2019, LNCS 11613, Springer Nature, Switzerland, pp. 186-202.

\section{Appendix A}

\begin{tabular}{|c|c|c|c|c|c|c|c|c|c|}
\hline \multirow{2}{*}{\begin{tabular}{|l|} 
PROJECT \\
2016 \\
\end{tabular}} & \multicolumn{3}{|c|}{ PARTICIPATION } & \multicolumn{3}{|c|}{ VIRTUALITY } & \multicolumn{3}{|c|}{ COLLABORATION } \\
\hline & St & SP & $\mathrm{Pa}$ & $\mathrm{Ph}$ & PV & $\mathrm{Vi}$ & In & IC & Co \\
\hline TangiWeb & & & $\mathrm{x}$ & & $\mathrm{x}$ & & & $\mathrm{x}$ & \\
\hline WindiCity & & $\mathrm{x}$ & & $\mathrm{x}$ & & & & $\mathrm{x}$ & \\
\hline Interactive Mirror & $\mathrm{x}$ & & & & & $\mathrm{x}$ & & $x$ & \\
\hline Goldilocks & & $\mathrm{x}$ & & & $\mathrm{x}$ & & & & $\mathrm{X}$ \\
\hline MarsRover & & $\mathrm{x}$ & & & $\mathrm{x}$ & & & $\mathrm{x}$ & \\
\hline ARubik & $\mathrm{x}$ & & & & $\mathrm{x}$ & & $\mathrm{x}$ & & \\
\hline OceanCleanUp & $\mathrm{x}$ & & & & & $\mathrm{x}$ & $x$ & & \\
\hline Gamified Story Gathering & $\mathrm{x}$ & & & & $\mathrm{x}$ & & & & $x$ \\
\hline VRM & $\mathrm{x}$ & & & & & $\mathrm{x}$ & & & $\mathrm{X}$ \\
\hline Roblox & $x$ & & & & $\mathrm{x}$ & & & $\mathrm{x}$ & \\
\hline \multicolumn{10}{|l|}{2017} \\
\hline Animal Vision & & $\mathrm{x}$ & & & $\mathrm{x}$ & & $\mathrm{x}$ & & \\
\hline MusiColor & & & $x$ & & $x$ & & & $x$ & \\
\hline Mission Mars & $\mathrm{x}$ & & & & & $\mathrm{x}$ & & & $\mathrm{X}$ \\
\hline Farmkampen & & $\mathrm{x}$ & & & & $\mathrm{x}$ & & $\mathrm{x}$ & \\
\hline Reforestation Game & $x$ & & & & $\mathrm{x}$ & & $\mathrm{x}$ & & \\
\hline Step & $\mathrm{x}$ & & & & & $\mathrm{x}$ & $\mathrm{x}$ & & \\
\hline Lightspeed on a bike & & $\mathrm{x}$ & & & $\mathrm{x}$ & & & $x$ & \\
\hline Surgeon Academy & $\mathrm{x}$ & & & & $\mathrm{x}$ & & $\mathrm{x}$ & & \\
\hline LaserGolf & $\mathrm{x}$ & & & $\mathrm{x}$ & & & & $\mathrm{x}$ & \\
\hline Mars Next & & $\mathrm{x}$ & & & $\mathrm{x}$ & & & $\mathrm{x}$ & \\
\hline \multicolumn{10}{|l|}{2018} \\
\hline VR Escape & $x$ & & & & $x$ & & & & $\mathrm{X}$ \\
\hline Zombie Outbrake & $\mathrm{x}$ & & & & $\mathrm{x}$ & & & & $\mathrm{X}$ \\
\hline Releaf & & & $x$ & & $x$ & & & $\mathrm{x}$ & \\
\hline Pathfinder & & $\mathrm{x}$ & & & & $x$ & & $x$ & \\
\hline Sensor Game & $x$ & & & & & $x$ & $\mathrm{x}$ & & \\
\hline Muffin or Chihuahua & $x$ & & & & $\mathrm{x}$ & & & $x$ & \\
\hline SNAP & & & $\mathrm{x}$ & & $\mathrm{x}$ & & $\mathrm{x}$ & & \\
\hline Saved by Sensors & $\mathrm{x}$ & & & & $\mathrm{x}$ & & $\mathrm{x}$ & & \\
\hline Cube Fusion & $x$ & & & & & $\mathrm{x}$ & & & $\mathrm{X}$ \\
\hline Robopop & & & $x$ & & $x$ & & & & $\mathrm{X}$ \\
\hline In your face & & & $\mathrm{x}$ & & & $\mathrm{x}$ & & $x$ & \\
\hline Sense of Taste & & $\mathrm{x}$ & & & $\mathrm{x}$ & & & & $\mathrm{x}$ \\
\hline SpaceTex & $\mathrm{x}$ & & & & & $\mathrm{x}$ & $\mathrm{x}$ & & \\
\hline \multicolumn{10}{|l|}{2019} \\
\hline Visualizing Vibrations & & & $\mathrm{x}$ & $\mathrm{x}$ & & & & $\mathrm{x}$ & \\
\hline War inside your body & $x$ & & & & & $x$ & $\mathrm{x}$ & & \\
\hline States of Matter & $\mathrm{x}$ & & & & $\mathrm{x}$ & & $\mathrm{x}$ & & \\
\hline Cyborg labyrinth & $x$ & & & $\mathrm{x}$ & & & $\mathrm{x}$ & & \\
\hline Radiation Platformer & $\mathrm{x}$ & & & & & $\mathrm{x}$ & $\mathrm{x}$ & & \\
\hline Radiation Stop Game & $\mathrm{x}$ & & & & & $\mathrm{x}$ & $\mathrm{x}$ & & \\
\hline Northern light & & & $\mathrm{x}$ & & $\mathrm{x}$ & & & $x$ & \\
\hline Twin star supernova & & $\mathrm{x}$ & & & & $x$ & & & $\mathrm{X}$ \\
\hline Arecibo message & $\mathrm{x}$ & & & & & $\mathrm{x}$ & $\mathrm{x}$ & & \\
\hline Digestive system & $x$ & & & & $x$ & & & $\mathrm{x}$ & \\
\hline Entanglement game & $x$ & & & & & $\mathrm{x}$ & & & $x$ \\
\hline Trampoline Grabity & $x$ & & & & $x$ & & $x$ & & \\
\hline
\end{tabular}

